\title{
Communicator Frog, to be a Catcher or a Frog Itself
}

\author{
Geon Ho Bahn \\ Editor-in-Chief, Korean Academy of Child and Adolescent Psychiatry
}

I have been to the 6th World Congress on ADHD, held in Vancouver, Canada on April. At the Congress, adult onset or later onset ADHD was receiving a close review. Because child psychiatrists considered ADHD as a disorder of childhood onset, the topic was interesting and yet up for a heating debate. Possibility of adult onset ADHD is as radical as categorizing what was considered as pervasive developmental disorder in DSM-IV to into autism spectrum disorder in DSM-5. Even the epidemiology of autism has exploded up to tens of times during the last half century. It means that the theory and the concept of children's mental health are ever changing as its subject of interest.

It may be the reason why clinicians often feel the diagnostic criteria of DSM or ICD falls short in practice. There are also culturally dependent diagnostic criteria such as 'driven-by motor' in ADHD. Since theories and diagnostic criteria vary over time and differ culturally, physicians often need personal understanding to be applied in practice. Physicians must be vigilant for a possibility of encountering a patient with 'never-known' disorder as Leo Kanner had met Donald Tripplett, the first diagnosed autism patient on 1938. With given diversity and an enormous quantity of cases, Korean psychiatrists can easily apply new medical knowledge in daily settings. This newly gained information should be shared with other physicians. To do so, attending international academic meetings and writing articles in English are required. This raises a discussion whether to publish the Journal of Korean Academy of Child and Adolescent Psychiatry (JKACAP) in English. The editorial committee of JKACAP has decided to publish each English and Korean paper twice a year as a transit solution since January 2017. This volume, published on 1st July, will be the second English only volume.
In this volume, the first paper is a review on the 'Impact of Childhood Exposure to Intimate Partner Violence and Other Adversities' on the health and well-being of the human family, written by Agnes Tiwari and her colleagues. Professor Tiwari is a key member of boards of 'the Academy on Violence and Abuse (AVA).' AVA members have already published three reviews in JKACAP last January and the editorial committee will work in hand with AVA to study the connection between childhood adversities and mental health.

There are three original articles. Yeeun Lee investigated 'Familial, Cognitive, and Behavioral Characteristics of Adolescents with Depression' and found negative self-cognition and suppression of emotion associated with adolescent depression. Eun Kyung Lee wrote 'The Development of a Computerized Comprehensive Learning Test' for detecting learning disabilities in mathematics in children and adolescents. Seong Woo Cho submitted 'Comparison of Adults with Attention-Deficit Hyperactivity Disorder Depending on the Age of Being Diagnosed in Childhood and Adulthood: Based on a Retrospective Review in One University Hospital', which is related to the previously mentioned controversial issue of later-onset ADHD.

While in Vancouver, I saw a sculpture named "Haida raven and first men" by Bill Reid at the Museum of Anthropology at the University of British Columbia. According to the legend of West Coast Natives (Haida), the raven gave the birth to the first men, and the Frog was the communicator between mother earth and mankind. Also, the Frog is a symbol of prosperity, wealth and good luck in Haida. 'Sleepless in Vancouver', I could not stop pondering upon the Frog. To activate JKACAP, we need the communicator frog between JKACAP and the subscribers. To be a frog catcher or a frog itself? 